\title{
Genetic variation of the green chafer, Anomala albopilosa (Hope) (Coleoptera: Scarabaeidae), in the Ryukyu Islands of Japan detected by mitochondrial DNA sequences
}

\author{
Masahiko MuraJi, ${ }^{1, *}$ Norio AraKaki, ${ }^{2}$ Suguru OHNo ${ }^{2}$ and Yoshio Hirai ${ }^{1, \dagger}$ \\ ${ }^{1}$ National Institute of Agrobiological Sciences; Ibaraki 305-8634, Japan \\ ${ }^{2}$ Okinawa Prefectural Agricultural Research Center; Okinawa 901-0336, Japan \\ (Received 3 July 2007; Accepted 31 January 2008)
}

\begin{abstract}
In the Ryukyu Islands of Japan, larvae of the green chafer Anomala albopilosa (Hope) are known as a serious pest of sugarcane. Based on sequences of mitochondrial ribosomal RNA genes obtained from specimens collected in this and adjacent areas, the phylogenetic relationships among local populations and geographic distribution patterns of haplotypic groups were examined. As a result, individuals were divided into five groups of haplotypes (Groups A-E). The shape of the phylogenetic trees suggested that they have been separated for a long period in their evolutionary history. Among the three groups distributed in the Ryukyu Islands, Groups B and D were restricted to the northern Amami region and Yaeyama region, respectively, while the range of Group $\mathrm{C}$ extended from the Amami to Yaeyama regions through the Okinawa and Miyako regions and largely overlapped the other two groups. This result was considered to suggest that the insular populations of this species were genetically muddled by the recent expansion of Group $\mathrm{C}$ that probably originated in the Okinawa region in the central Ryukyu Islands. Causes of these phenomena are discussed in relation to the food habits of this species and the paleogeography of this area.
\end{abstract}

Key words: Sugarcane pest; haplotypic groups; population expansion

\section{INTRODUCTION}

The green chafer, Anomala albopilosa (Hope), is distributed in Eastern Asia, including Japan, Taiwan, and Korea. On the Japanese mainland, larvae of this species are found in leaf mold and sometimes injure roots of nursery-grown tree seedlings (Aino et al., 1956) and sweet potatoes (Yamashita et al., 1998). On the other hand, in the Ryukyu Islands of Japan, this species is known as one of the most destructive pests of the sugarcane crop. Its larvae, a sugarcane white grub, feed on the roots of sugarcane and cause wilting and deterioration of stalks (Arakaki et al., 2004). Their populations often occur at very high density and cause considerable economic damage to the crop. This species is considered to have become a destructive pest after sugarcane strains and cultivation methods were altered around 1960 (Hokyo and Nagamine,
1978). Dense population outbreaks occurred in the 1970s and 1980s in distantly separated islands, such as Okinoerabu-jima, Okinawa-jima, Miyakojima, and Ishigaki-jima (Hokyo and Nagamine, 1978; Sadoyama et al., 2001).

In the area between the Japanese mainland and Taiwan, taxonomists have recognized six different subspecies. In addition to subspecies on the Japanese mainland, A. a. albopilosa (Hope), and in Taiwan, $A$. a. trachypyga (Bates), four subspecies, $A$. a. gracilis Schönfeldt, A. a. yashironi Sawada, A. a. sakishimana Nomura, and A. a. yonaguniana Nomura, have been recognized in the Ryukyu Islands (Kobayashi, 1985; Fujioka, 2001). Because these insular subspecies were described from 1890 to 1964 (Fujioka, 2001), they are considered to reflect the geographic variation of this species before its local populations experienced the continuous outbreaks occurring in the last half of the 20th cen-

\footnotetext{
* To whom correspondence should be addressed at: E-mail: mmuraji@affrc.go.jp

${ }^{\dagger}$ Present address: Sena 7-12-11, Aoi-ku, Shizuoka 420-0911, Japan

DOI: 10.1303/aez.2008.299
} 
tury. Therefore, it is unclear whether the outbreaks occurred independently in geographically separated subspecies. It is also unclear whether each subspecies retained its genetic integrity even after the population explosion. In order to study the causes and consequences of outbreaks of this species, it is vital to examine the relationships among local populations occurring in the Ryukyu Islands.

In this study, we examined nucleotide sequences of the mitochondrial DNA (mtDNA) fragment containing portions of $16 \mathrm{~S}$ and $12 \mathrm{~S}$ ribosomal RNA genes (rDNAs) using specimens collected from the Ryukyu Islands and adjacent areas. Our objectives were 1) to examine genetic variations among individuals, 2) to examine relationships among haplotypic groups, and 3) to examine the geographic patterns of these groups. As a result, we found that individuals in the Ryukyu Islands were divided into three groups and that their ranges do not exactly coincide with those of subspecies known from this area. Based on these results, we discuss the factors affecting the genetic divergence and unique distribution patterns of mtDNA types among insular populations of $A$. albopilosa.

\section{MATERIALS AND METHODS}

Adults of A. albopilosa were collected from 24 localities (Table 1) in the Ryukyu Islands and adjacent regions (Fig. 1). In this area, local populations are known to be divided into six subspecies: $A$. $a$. albopilosa, A. a. gracilis, A. a. yashironi, A. a. sakishimana, $A$. a. yonaguniana, and $A$. a. trachypyga (Table 1). These subspecies were originally described based on differences in morphological characteristics, such as the shape of the elytral epipleura and elytral marginal membrane (Kobayashi, 1985). However, because we could not unambiguously divide the specimens into subspecies, we treated all the specimens as a single species. The cupreous chafer Anomala cuprea Arrow was used as an outgroup taxon. This species showed the closest relationship with $A$. albopilosa among several other Anomala species collected in the Ryukyu Islands (Muraji, unpublished). Specimens were stored in $99.9 \%$ ethanol. Template DNA was extracted from the legs of individuals using a GenomicPrep Cell \& Tissue DNA Isolation Kit (Amersham Biosciences, Buckinghamshire, UK) and dissolved in $200 \mu \mathrm{l}$ sterilized distilled water.

Amplification of a mtDNA fragment containing portions of $16 \mathrm{~S}$ rDNA and $12 \mathrm{~S}$ rDNA was performed using two PCR primers, AAMT12948F (5'

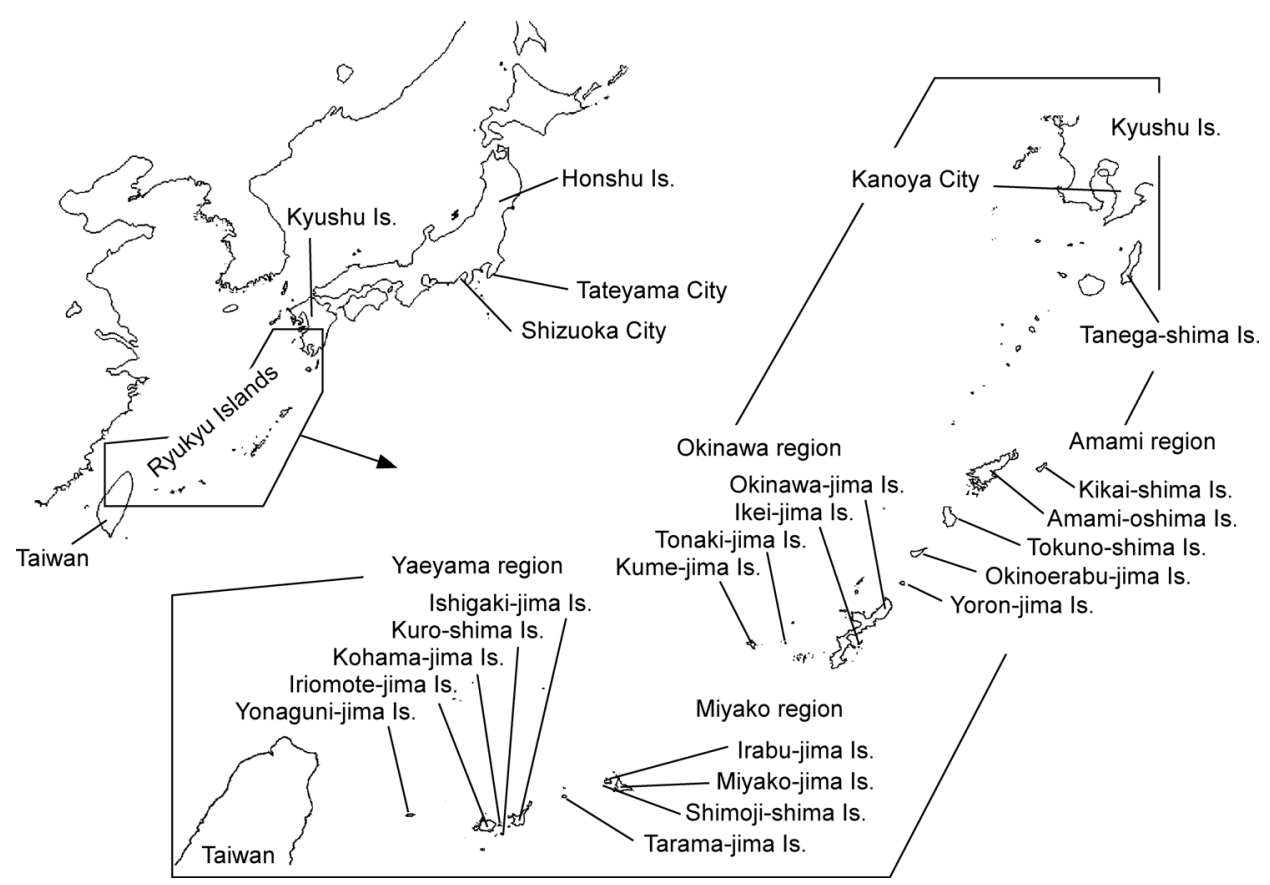

Fig. 1. Map showing localities where the materials were collected. 
Table 1. Materials used in this study

\begin{tabular}{|c|c|c|c|c|c|}
\hline Species & Locality & Code & Date & Collection & $\begin{array}{l}\text { Subspecies } \\
\text { expected }^{\mathrm{a}}\end{array}$ \\
\hline \multicolumn{6}{|l|}{ Anomala albopilosa } \\
\hline \multicolumn{6}{|l|}{ Japanese mainland } \\
\hline \multirow[t]{2}{*}{ Honshu Island } & Tateyama City, Chiba Pref. & TTY & 04. VII. 16 & Mihira & 1 \\
\hline & Shizuoka City, Shizuoka Pref. & SZO & 04. VII. 24 & Hirai & 1 \\
\hline \multirow[t]{2}{*}{ Kyushu Island } & Kushira, Kanoya City, Kagoshima Pref. & KSRa & 04. VII. 1 & Takesaki & 1 \\
\hline & Kushira, Kanoya City, Kagoshima Pref. & $\mathrm{KSRb}$ & 04. VII. 28 & Hirai & 1 \\
\hline Tanega-shima Island & Nishino-omote City, Kagoshima Pref. & $\mathrm{TNG}$ & 04. VI. 22 & Irei & 1 \\
\hline \multicolumn{6}{|l|}{ Ryukyu Islands } \\
\hline \multicolumn{6}{|l|}{ Amami region } \\
\hline Amami-oshima Island & Naze, Amami City, Kagoshima Pref. & AMM & 04. VII. 2 & Hayashikawa & 2 \\
\hline Tokuno-shima Island & Isen Town, Kagoshima Pref. & TKN & 04. VI. 13 & Takemure & 2 \\
\hline Kikai-shima Island & Kikai Town, Kagoshima Pref. & KKS & 04. VII. 28 & Yoshioka & 2 \\
\hline \multirow[t]{2}{*}{ Okinoerabu-jima Island } & Wadomari Town, Kagoshima Pref. & OKEa & 04. VI. 23 & Arakaki & 3 \\
\hline & Wadomari Town, Kagoshima Pref. & $\mathrm{OKEb}$ & 05. VI. 16 & Arakaki & 3 \\
\hline Yoron-jima Island & Yoron Town, Kagoshima Pref. & YRN & 04. VII. 7 & Mori & 3 \\
\hline \multicolumn{6}{|l|}{ Okinawa region } \\
\hline \multirow[t]{2}{*}{ Okinawa-jima Island } & Itoman City, Okinawa Pref. & OKWa & 04. VI. 13 & Arakaki & 3 \\
\hline & Okuma, Kunigami Village, Okinawa Pref. & $\mathrm{OKWb}$ & 05. VII. 1 & Arakaki & 3 \\
\hline Ikei-jima Island & Ikei, Uruma City, Okinawa Pref. & IKJ & 04. VI. 16 & Arakaki & 3 \\
\hline \multirow[t]{3}{*}{ Kume-jima Island } & Kumejima City, Okinawa Pref. & KMJa & 04. VI. 4 & Kohama & 3 \\
\hline & Kumejima City, Okinawa Pref. & $\mathrm{KMJb}$ & 05. V. 31 & Haraguchi & 3 \\
\hline & Kumejima City, Okinawa Pref. & KMJc & 05. VI. 13 & Ohno & 3 \\
\hline Tonaki-jima Island & Tonaki Village, Okinawa Pref. & TNK & 04. VII. 5 & Ohno, Sugaya & 3 \\
\hline \multicolumn{6}{|l|}{ Miyako region } \\
\hline Miyako-jima Island & Nishizato, Miyakojima City, Okinawa Pref. & MYK & 04. V. 17 & Arakaki & 4 \\
\hline Irabu-jima Island & Irabu, Miyakojima City, Okinawa Pref. & IRB & 04. V. 17 & Oota & 4 \\
\hline Shimoji-shima Island & Shimoji, Miyakojima City, Okinawa Pref. & SMJ & 05. VI. 2 & Ohno & 4 \\
\hline Tarama-jima Island & Tarama Village, Okinawa Pref. & TRM & 05. VI. 3 & Sakiyama & 4 \\
\hline \multicolumn{6}{|l|}{ Yaeyama region } \\
\hline Ishigaki-jima Island & Arakawa, Ishigaki City, Okinawa Pref. & ISG & 04. VI. 4 & Tanizaki & 4 \\
\hline Iriomote-jima Island & Funaura, Taketomi Town, Okinawa Pref. & IRO & 04. V. 30 & Ohno & 4 \\
\hline Kuro-shima Island & Kuroshima, Taketomi Town, Okinawa Pref. & KRS & 05. V. 28 & Ohno & 4 \\
\hline Kohama-jima Island & Kohama, Taketomi Town, Okinawa Pref. & KHM & 05. V. 27 & Ohno & 4 \\
\hline \multirow[t]{2}{*}{ Yonaguni-jima Island } & Sonai, Yonaguni Town, Okinawa Pref. & YNGa & 04. VI. 8 & Kuba & 5 \\
\hline & Sonai, Yonaguni Town, Okinawa Pref. & YNGb & 05. VI. 20 & Yasuda & 5 \\
\hline Taiwan & Puli Township, Nantou County, Taiwan & TWN & 04. VII. 28 & Haraguchi & 6 \\
\hline \multicolumn{6}{|l|}{ Anomala cuprea } \\
\hline \multicolumn{6}{|l|}{ Japanese mainland } \\
\hline Honshu Island & Shizuoka City, Shizuoka Pref. & ACS & 04. VII. 24 & Hirai & \\
\hline \multicolumn{6}{|l|}{ Ryukyu Islands } \\
\hline \multicolumn{6}{|l|}{ Okinawa region } \\
\hline Okinawa Island & Motobu Town, Okinawa Pref. & $\mathrm{ACO}$ & 04. VI. 17 & Kawamura & \\
\hline
\end{tabular}

\footnotetext{
${ }^{a}$ Numerals 1-6 indicate six subspecies expected for each locality. 1: A. a. albopilosa, 2: A. a. gracilis, 3: A. a. yashironi, 4: A. a. sakishimana, 5: A. a. yonaguniana, and 6: A. a. trachypyga. Their ranges were expected based on those described in Fujioka (2001) and Kobayashi (1985).
}

ATC CAA CAT CGA GGT CGC AAA CT 3') and AAMT14569R (5' GCT TGA ATA GTA GTA GTT ATG TTC TTG $3^{\prime}$ ). They were designed based on the sequences obtained in preliminary analysis using a set of universal primers $16 \mathrm{Fa} / 12 \mathrm{Rb}$
(Muraji and Nakahara, 2001). Amplification was carried out in a $20 \mu \mathrm{l}$ volume containing $1.0 \mu \mathrm{l}$ of DNA template, $1.0 \mu \mathrm{l}$ of each primer $(5 \mathrm{pmol} / \mu \mathrm{l})$, $2.0 \mu \mathrm{l}$ of $10 \times$ PCR buffer, $1.6 \mu \mathrm{l}$ of dNTPs $(2.5 \mathrm{~mm}$ each), and 0.12 unit of Ex-Taq DNA polymerase 
(TaKaRa-Bio, Otsu, Japan). Temperature cycling was carried out in a Program Temp Control System PC-805 (Astec Co., Ltd., Fukuoka, Japan). After a heating step at $92^{\circ} \mathrm{C}$ for $2 \mathrm{~min}$, samples were incubated for 35 cycles of $92^{\circ} \mathrm{C}$ for $1 \mathrm{~min}, 50^{\circ} \mathrm{C}$ for $30 \mathrm{~s}$, and $72^{\circ} \mathrm{C}$ for $2 \mathrm{~min}$. The purification, labeling, and sequencing of the PCR products were performed according to the method described in Muraji and Nakahara (2001). In addition to AAMT12948F and AAMT14569R, a primer AAMT13478F (5' CAT ATA CTA ATT TTA TCA TTA TTA C $3^{\prime}$ ), designed based on the sequences obtained in this study, was used for sequencing. Sequences obtained from representative individuals were submitted to DDBJ/EMBL/GenBank nucleotide sequence databases (Accession numbers: AB330384-AB330391).

Nucleotide sequences were aligned using Genetyx-Mac ver. 10 (Genetyx Co., Tokyo, Japan) and modified by manual optimization. The aligned sequences were used to compute basic statistical data by MEGA ver. 3.1 software (Kumar et al., 2004). This program was also used to generate phylogenetic trees based on the neighbor-joining method and to test the robustness of trees by 1,000 replications of bootstrapping. Maximum parsimony analyses were performed with PAUP* ver. $4.0 \mathrm{~b} 10$ (Swofford, 2003), using a heuristic search procedure with TBR swapping and 100 max tree options. For maximum likelihood analysis, the appropriate model for nucleotide substitutions $(\mathrm{HKY}+\mathrm{I}+\mathrm{G})$ and parameters used for tree construction was selected by hierarchical likelihood ratio tests using PAUP with MrModeltest 2.2 (Nylander, 2004). The maximum likelihood tree was generated using PAUP with heuristic searches and the first stepwise addition.

\section{RESULTS}

\section{Nucleotide sequences}

The nucleotide sequences of the mtDNA from $16 \mathrm{~S}$ to $12 \mathrm{rDNA}$ (16S-12S) were determined for 119 A. albopilosa and 5 A. cuprea individuals. The data set of $1,521 \mathrm{bp}$ in length was generated by compiling sequences from which data at the $5^{\prime}$ and $3^{\prime}$ ends were excluded. When sequences of A. albopilosa were compared, 4, 73, and 50 insertion/deletion sites, substitutional polymorphic sites, and parsimony informative sites, respectively, were detected. Substitutions were biased toward transitions $(67 \%)$. The nucleotide compositions of the sequences were biased to $\mathrm{A}$ and $\mathrm{T}(\mathrm{A}+\mathrm{T}: 77.0 \%)$.

\section{Phylogenetic analyses}

The topologies of phylogenetic trees based on the neighbor-joining method (Fig. 2) were consistent among the methods used for calculating genetic distances in terms of the relationships among

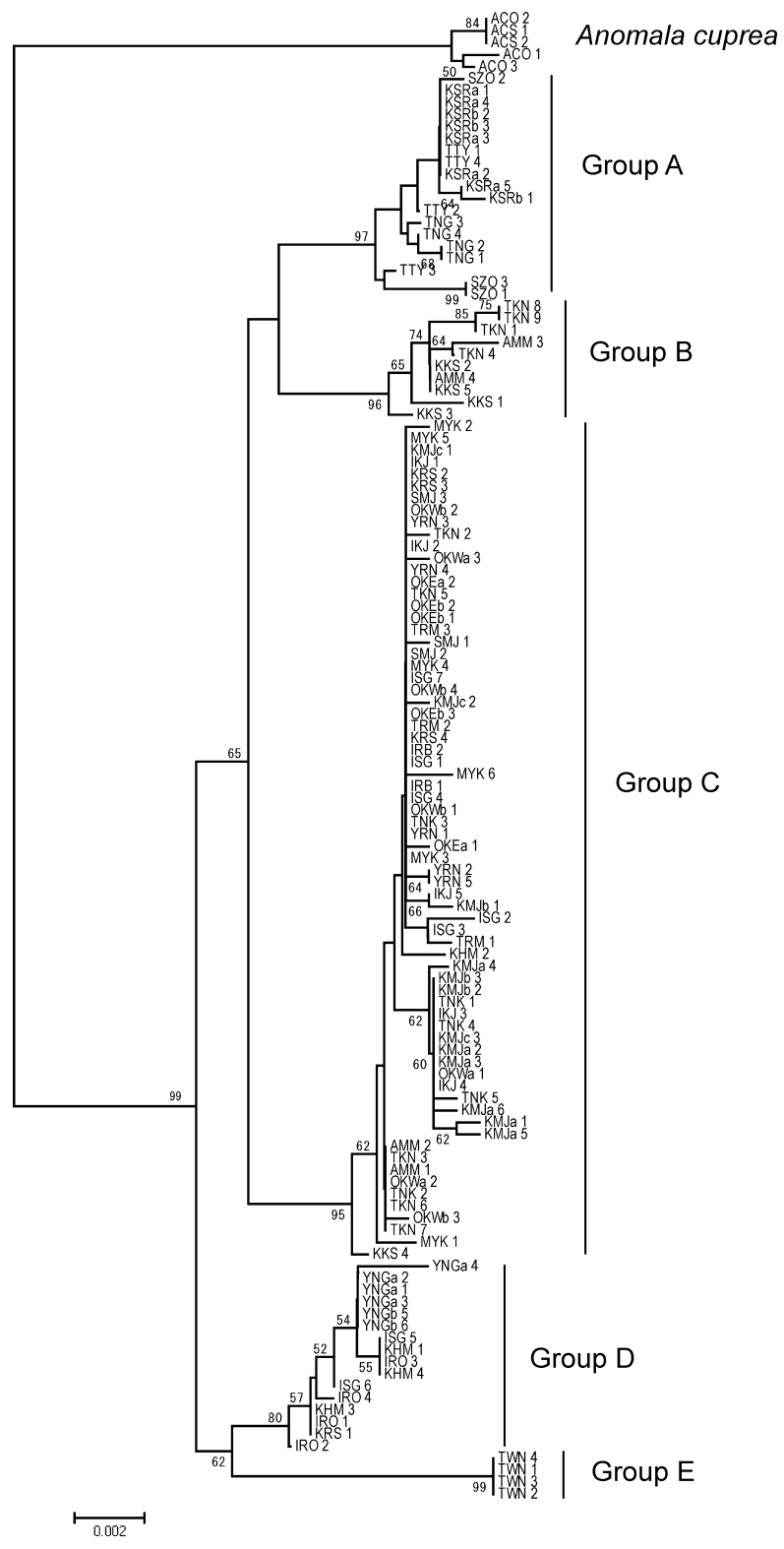

Fig. 2. Neighbor-joining tree based on the Jukes-Cantor distances calculated using $1,521 \mathrm{bp}$-long sequences of the mtDNA from 16S to $12 \mathrm{~S}$ rDNA. Bootstrap confidence levels calculated based on 1,000 replications are shown near the nodes. 
sequences supported by bootstrap confidence levels higher than $60 \%$. These trees indicated five discretely separated groups among the sequences of A. albopilosa: these were denoted as Groups A, B, $\mathrm{C}, \mathrm{D}$, and E. Results of the maximum parsimony and maximum likelihood analyses agreed well with those of neighbor joining analysis in terms of the grouping of sequences. In the former analysis, the 64 most parsimonious trees were detected (length: 135; CI: 0.785; RI: 0.971; RC: 0.762) and were different only in terms of the relationships among sequences within a group. However, the relationships among the five groups were not consistent among the phylogenetic trees obtained by the three different methods. In these trees, basal nodes connecting the five groups were separated by rather short branches.

\section{Geographic distribution of haplotypic groups}

Among the five haplotypic groups detected in the phylogenetic analyses, Groups A and E were distributed on the Japanese mainland (including Tanega-shima Island) and Taiwan, respectively (Fig. 3). The three others, Groups B, C, and D, were distributed in the Ryukyu Islands. Of these, Groups B and D were exclusively detected in the northern part of the Amami region (islands of Tokuno-shima, Amami-oshima, and Kikai-shima) and Yaeyama region, respectively. Group $\mathrm{C}$ was detected in most parts of the Ryukyu Islands, exclud- ing the western part of the Yaeyama region (Iriomote-jima and Yonaguni-jima). Thus, in the northern part of the Amami region, each population contained both Groups B and C. The populations of Ishigaki-jima, Kuro-shima, and Kohamajima in the eastern part of the Yaeyama region contained both Groups D and C. Populations in the Okinawa and Miyako regions, and the southern part of the Amami region (Okinoerabu-jima and Yoron-jima) contained only sequences of Group C.

Ranges of the three subspecies, A. a. albopilosa, A. a. gracilis, and A. a. trachypyga corresponded to those of Groups A, B, and E, respectively (Fig. 3); however, as mentioned above, the coexistence of two different groups was detected in the range of A. a. gracilis (northern part of the Amami region). In the range of $A$. a. sakishimana, two different haplotypic groups were detected. Within that range, populations in the Miyako region and Iriomote-jima Island exclusively contained sequences of Groups C and D, respectively, while those of other islands (Ishigaki-jima, Kohama-jima, and Kuro-shima) contained both of these groups. In the range of $A$. a. yonaguniana, i.e., Yonaguni-jima at the western end of the Yaeyama region, no specific haplotypic group was detected. Sequences on this island were not clearly separated from those on neighboring islands such as Ishigaki-jima and Iriomote-jima (Fig. 2).

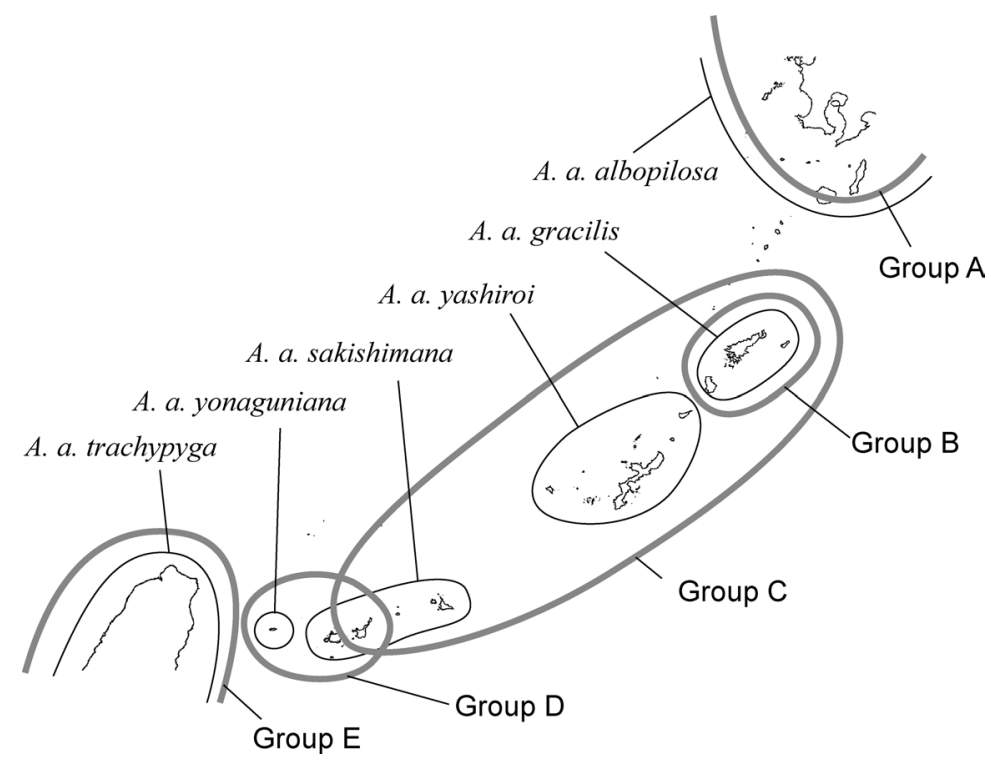

Fig. 3. Map showing geographic ranges of the five haplotypic groups detected in this study (thick lines) and those of six known subspecies of A. albopilosa (thin lines). The ranges of the subspecies were drawn mainly from Fujioka (2001). 


\section{DISCUSSION}

In this study, we found five haplotypic groups among individuals collected from the area between the Japanese mainland and Taiwan (Fig. 3). Although the ranges of two of the groups, Groups A and $\mathrm{E}$, coincided with those of subspecies known from the Japanese mainland (A. a. albopilosa) and Taiwan (A. a. trachypyga), respectively, the distribution patterns of Groups B, C, and D in the Ryukyu Islands did not precisely coincide with those of subspecies known from this area. In particular, Group $\mathrm{C}$ was distributed widely across the ranges of three insular subspecies, $A$. a. gracilis, $A$. a. yashironi, and A. a. sakishimana. The range of A. a. yonaguniana, which is endemic to Yonagunijima, was occupied by Group D, a group commonly seen in neighboring islands. According to the definition advocated by Mayr and Ashlock (1991), a subspecies is an aggregate of local populations of a species inhabiting a geographic subdivision of the range of the species and differing taxonomically from other populations. Thus, the existence of several different subspecies indicates that their populations are divided among geographic regions. However, the present study did not support the separation of local populations of A. albopilosa in the Ryukyu Islands. One possible explanation for this phenomenon is that the populations were originally divided among geographic regions where mtDNA sequences diverged, and then their separation was disrupted by the dispersal of insects in the Ryukyu Islands.

In the phylogenetic tree shown in Fig. 2, individuals were clearly divided into five groups, suggesting that they have long been separated in their evolutionary history. Short distances between basal nodes connecting haplotypic groups suggest that they diverged within a rather short period. In the preliminary experiment, we determined a $1,308 \mathrm{bp}$ long sequence containing portions of the cytochrome $\mathrm{c}$ oxidase subunits I and II genes (AB330763-AB330767) for five individuals collected on the islands of Kyushu, Amamioshima, Okinawa-jima, Iriomote-jima, and Taiwan. Pairwise comparisons of 2,829 bp-long sequences, generated by concatenating these with $16 \mathrm{~S}-12 \mathrm{~S}$ sequences obtained from the same individuals, estimated substitution rates of $2.52-3.90 \%$ among the haplotypic groups. When an mtDNA evolutionary clock, $2.3 \%$ per million years, calibrated using various insect groups (Brower, 1994), was simply applied, a divergence time of 1.1-1.7 million years was estimated. Although the appropriateness of applying such molecular clocks, obtained from other taxonomic groups, to A. albopilosa is questionable, the estimated values suggest that haplotypic groups were probably separated one million years ago or earlier.

According to the hypothesis on the paleogeography of the Ryukyu Islands (Kimura, 1996, 2002), islands in this area, as well as land around the East China Sea, were connected by a large land mass in the late Pliocene (2.0-1.7 million years ago). Then, the area of the Islands partially separated from adjacent regions, forming a large peninsula extending from the Chinese continent through Taiwan. Due to extensive subsidence in the early Pleistocene (about 1.3 million years ago), the peninsula submerged to form a chain of small islands stretching between Taiwan and the Japanese mainland, which has continued for more than one million years. Thus, lands of the Ryukyu Islands are thought to have subdivided gradually from a large land mass into small islands from 1.7 to 1.3 million years ago. The results of the present study seem to be consistent with this hypothesis in that they suggest the haplotypic groups diverged within a rather short period about one million years ago or earlier.

For the land configuration in the late Pleistocene, Kizaki and Oshiro (1980) postulated the emergence of several large islands connecting neighboring islands. Lin et al. (2002) suggested the presence of three or four large islands approximately corresponding to the Amami, Okinawa, and Sakishima regions (Sakishima indicates the southwestern Ryukyu Islands, including both the Miyako and Yaeyama regions) based on molecular analyses of grass lizards. In this case, at least four straits, which separated the area into five regions, the Japanese mainland, Amami, Okinawa, Sakishima, and Taiwan, are considered to have acted as barriers of biological dispersal. Similar phenomena are widely observed in the distribution patterns of many groups of terrestrial animals in which species, subspecies, or mtDNA haplotypes are divided among the Ryukyu Islands and adjacent regions, and/or among three regions of the Islands (Ikehara, 1996; Ota, 1998; Maekawa et al., 1999; Fujioka, 2001; Hosoya and Araya, 2007). Thus, the 
five haplotypic groups in A. albopilosa might also have been caused by the separation of local populations due to the four longstanding straits.

In this study, the ranges of Groups A, B, D, and E approximately coincided with four of the five regions mentioned above (Fig. 3), and no specific group was detected in the Okinawa region of the central Ryukyu Islands. If all the groups originated in different regions, we might suppose that Group $\mathrm{C}$ originated in the Okinawa region and expanded its range into neighboring regions. If this were true, the original haplotype of the Miyako region in the southwestern Ryukyu Islands would have been eliminated by insects invading from the Okinawa region. The fact that the sequences of this group have not diverged strongly among remote islands (Fig. 2) suggests that their expansion might have occurred fairly recently. Because Okinawa Island, in the middle of the Ryukyu Islands, is the center of politics and economics in the Ryukyu Islands, it is not unreasonable that organisms specific to this region could have spread into neighboring regions in conjunction with human activities.

Sugarcane originated in southeast Asia and New Guinea (Lebot, 1999), and it is said that this plant was first introduced into the Ryukyu Islands from southern China in the 8th century (Hokyo and Nagamine, 1978). Because A. albopilosa is known only in East Asia, including Japan, Taiwan, and Korea (Fujioka, 2001), adaptation of this species to sugarcane must have occurred after the crop was introduced. Although no destructive economic damage was recorded for the subspecies $A$. a. trachypyga distributed in Taiwan, where sugarcane is also cultivated intensively, it is not clear whether its larvae can feed on the crop; however, the present study suggested that its population is separated from those of the Ryukyu Islands (Fig. 3). Thus, it seems unlikely that the adaptation occurred in Taiwan and was transmitted to the Ryukyu Islands.

The food plants of larvae of $A$. albopilosa differ between populations of the Japanese mainland and the Ryukyu Islands. The former population feeds on roots of trees (Aino et al., 1956) and the latter on roots of sugarcane. Injury to sweet potatoes was recorded for the former population (Yamashita et al., 1998), although the crop is widely cultivated in the Ryukyu Islands. In the case of the scarab beetle Dasylepida ishigakiensis (Niijima et Kinoshita) distributed in Miyako-jima, Ishigaki-jima and Iri- omote-jima (Fujioka, 2001), larvae of the Miyakojima population are known as a serious pest of sugarcane (Sadoyama et al., 2001). Although this crop is also cultivated over a large area in the latter two islands, populations of these islands occur only in natural forests of broad leaf trees (Hirai, 2001). These phenomena suggest that it is not very easy for grubs to change their eating habits. If this is true, it must have been difficult for populations of A. albopilosa to independently become sugarcane pests on distantly separated islands within a short period after the crop was introduced. Thus, the fact that populations on these islands are injuring the sugarcane crop (Hokyo and Nagamine, 1978) suggests that their food habits were transmitted through the movement of insects.

In the mid-1990s, A. cuprea, a close relative of A. albopilosa, invaded the northern part of Okinawa Island, probably from the Japanese mainland, due to human activities (Kawamura, 2001). Kawamura (2001) estimated that the range expanded for $10-20 \mathrm{~km}$ on the island over a period of 4 years. Arakaki et al. (2004) suggested that adults of $A$. albopilosa migrate between oviposition and copulation sites separated over a distance of several kilometers on Miyako-jima Island. These reports suggest that individual chafers rarely disperse far. Thus, the movements of $A$. albopilosa among islands were probably due to a small number of individuals accidentally transported by meteorological factors, such as typhoons, or human activities, including shipping plants with soil or leaf mold.

\section{ACKNOWLEDGEMENTS}

We thank the following for their kind cooperation with the collection of the beetles: K. Takesaki, S. Hayashikawa, and Y. Takemure of the Kagoshima Prefectural Agricultural Experiment Station, S. Irei of the National Agricultural Research Center for Kyushu Okinawa Region, K. Mori of the Kagoshima Prefectural Agricultural Extension Center, Y. Sakiyama of the Miyako Branch of Okinawa Prefectural Government, T. Yoshioka of the Kikai Town Office, S. Tanizaki in the Ishigaki City, T. Kohama, D. Haraguchi, T. Uesato, H. Sugaya of the Okinawa Prefectural Fruit-fly Eradication Project Office, M. Oota, S. Sakiyama, H. Kuba, K. Yasuda and F. Kawamura of the Okinawa Prefectural Agricultural Experiment Station, and T. Mihira of the Chiba Prefectural Agricultural Experiment Station. This study was supported in part by a Grant-in-Aid for Scientific Research (19580058) from the Ministry of Education, Culture, Sports, Science and Technology of Japan. 


\section{REFERENCES}

Aino, S., F. Yamada and N. Gokan (1956) Research on control measures against injurious insects that attack nursery stock-I. Ecological studies and chemical control of white grubs. Bull. For. For. Prod. Res. Inst. 91: 1-36 (in Japanese with English summary).

Arakaki, N., M. Kishita, A. Nagayama, M. Fukaya, H. Yasui, T. Akino, Y. Hirai and S. Wakamura (2004) Precopulatory mate guarding by the male green chafer, Anomala albopilosa sakishimana Nomura (Coleoptera: Scarabaeidae). Appl. Entomol. Zool. 39: 455-462.

Brower, A. V. Z. (1994) Rapid morphological radiation and convergence among races of the butterfly Heliconius erato inferred from patterns of mitochondrial DNA evolution. Proc. Natl. Acad. Sci. USA 91: 6491-6495.

Fujioka, M. (2001) A List of Japanese Lamellicornia. The Japanese Society of Scarabaeideans, Tokyo. 293 pp. (in Japanese).

Hirai, Y. (2001) A curious scarab beetle Dasylepida ishigakiensis, from Sakishima Islands, Okinawa Prefecture. Saikaku Tsushin 4: 27-32 (in Japanese).

Hokyo, N. and M. Nagamine (1978) Causes and measures for outbreaks of Anomala albopilosa in Okinawa. Shokubutsu Boeki 32: 267-272 (in Japanese).

Hosoya, T. and K. Araya (2007) Molecular phylogeography of the genus Neolucanus in the Ryukyu Archipelago. The Nature and Insect 41(4): 5-10 (in Japanese).

Ikehara, S. (1996) Islands of valuable animals: fauna of the Ryukyu Archipelago. In Nature in Japan, 8. Southern Islands (K. Nakamura, H. Ujiie, S. Ikehara, H. Tagawa and N. Hori eds.). Iwanami-Shoten, Tokyo, pp. 149-160 (in Japanese).

Kawamura, F. (2001) Distribution of the invasive pest, Anomala cuprea Arrow (Coleoptera: Scarabaeidae), in the Island of Okinawa. Bull. Okinawa Agric. Exp. Sta. 23: 61-63 (in Japanese with English summary).

Kimura, M. (1996) Quaternary paleogeography of the Ryukyu Arc. J. Geography 105: 259-285 (in Japanese with English summary).

Kimura, M. (2002) Paleogeography and Organisms Migration of the Ryukyu Arc. Okinawa Times, Naha. 206 pp. (in Japanese).

Kizaki, K. and I. Oshiro (1980) The origin of the Ryukyu Islands. In Natural History of Ryukyu (K. Kizaki ed.).
Tsukiji-Shokan, Tokyo, pp. 8-37 (in Japanese).

Kobayashi, H. (1985) Scarabaeidae. In The Coleoptera of Japan in Colour. Vol. II (S. Ueno, Y. Kurosawa and M. Sato eds.). Hoikusha Publishing, Osaka, pp. 381-419 (in Japanese).

Kumar, S., K. Tamura and M. Nei (2004) MEGA3: Integrated software for molecular evolutionary genetics analysis and sequence alignment. Brief. Bioinform. 5: 150-163.

Lebot, V. (1999) Biomolecular evidence for plant domestication in Sahul. Genet. Resour. Crop Evol. 46: 619-628.

Lin, S.-M., C. A. Chen and K.-Y. Lue (2002) Molecular phylogeny and biogeography of the grass lizards genus Takydromus (Reptilia: Lacertidae) of East Asia. Mol. Phylogenet. Evol. 22: 276-288.

Maekawa, K., N. Lo, O. Kitade, T. Miura and T. Matsumoto (1999) Molecular phylogeny and geographic distribution of wood-feeding cockroaches in East Asian Islands. Mol. Phylogenet. Evol. 13: 360-376.

Mayr, E. and P. D. Ashlock (1991) Principles of Systematic Zoology. 2nd ed. McGraw Hill Inc, New York. 475 pp.

Muraji, M. and S. Nakahara (2001) Phylogenetic relationships among fruit flies, Bactrocera (Diptera, Tephritidae), based on the mitochondrial rDNA sequences. Insect Mol. Biol. 10: 549-559.

Nylander, J. A. A. (2004) MrModeltest v2. Program distributed by the author. Evolutionary Biology Centre, Uppsala University.

Ota, H. (1998) Geographic patterns of endemism and speciation in amphibians and reptiles of the Ryukyu archipelago, Japan, with special reference to their paleogeographical implications. Res. Popul. Ecol. 40: 189-204.

Sadoyama, Y., H. Oroku and H. Nakamori (2001) Injury of sugar cane roots by the white grub, Dasylepida sp. (Coleoptera: Scarabaeidae), in the Miyako Islands. Jpn. J. Appl. Entomol. Zool. 45: 89-91 (in Japanese with English summary).

Swofford, D. L. (2003) PAUP*. Phylogenetic Analysis Using Parsimony (*and Other Methods). Version 4. Sinauer Associates, Massachusetts.

Yamashita, T., O. Setoguchi, H. Kamiwada and K. Kushigemati (1998) Annual occurrence of Anomala albopilosa Hope (Coleoptera: Scarabaeidae) in southern Kyushu. Kyushu Pl. Prot. Res. 44: 67-71 (in Japanese). 